\title{
A luta dos povos indígenas por saúde em contextos de conflitos ambientais no Brasil (1999-2014)
}

\author{
The struggle of indigenous peoples for health \\ in environmental conflict contexts in Brazil (1999-2014)
}

Diogo Ferreira da Rocha ${ }^{1}$

Marcelo Firpo de Souza Porto ${ }^{1}$

Tania Pacheco ${ }^{1}$

${ }^{1}$ Escola Nacional de Saúde Pública Sérgio Arouca, Fiocruz. R. Leopoldo Bulhões 1480, Manguinhos. 21041-210 Rio de Janeiro RJ Brasil.diogoferreira@ posgrad.ensp.fiocruz.br

\begin{abstract}
The Brazilian development model, based on commodities and electro-intensive industries for trade in global markets, generates social and environmental inequalities that trigger various conflicts between indigenous peoples and communities and economic groups involving disputes over territory and common assets in contexts that influence the health situation of these communities. The objective of this paper is to present an overview of environmental conflicts involving the Brazilian indigenous peoples, their strategies to ensure the sustainability and demarcation of their territories and discuss the forms of pressure of the population on this Subsystem of Indigenous Healthcare (SASI) or alternatives they have proposed to tackle the problems generated. This analysis is based on a mapping of environmental conflicts based on the bibliographical revision of secondary sources (by indigenous movements or their partners) that supported the construction of reports on conflicts and analysis of the indigenous narratives about the territory where they live and their struggles. The conclusion drawn is that the health control strategies of Brazilian indigenous peoples are influenced by their socio-environmental disputes and are part of the mobilization of these peoples for the full recognition of their rights. Key words Environmental conflicts, Indigenous peoples, Indigenous health
\end{abstract}

Resumo O modelo de desenvolvimento brasileiro, fortemente baseado na produção de commodities e em indústrias eletrointensivas para trocas nos mercados globais, gera desigualdades sociais e ambientais que desencadeiam diversos conflitos entre povos indígenas e grupos econômicos envolvendo disputas por terra e bens comuns em contextos que influenciam fortemente a situação de saúde dessas comunidades. O objetivo deste artigo é apresentar um panorama dos conflitos socioambientais envolvendo os povos indigenas brasileiros, suas estratégias para garantir o acesso e a qualidade do Subsistema de Atenção à Saúde Indígena (SASI), e alternativas que eles têm proposto para o enfrentamento dos problemas gerados. Esta análise se baseia em um mapeamento de conflitos ambientais baseado na revisão bibliográfica de fontes secundárias (do movimento indígena ou seus parceiros) que subsidiaram a construção de relatos sobre os conflitos e a análise das narrativas indigenas sobre o território onde vivem e suas lutas. A partir da qual concluímos que as estratégias de luta pela saúde dos povos indígenas brasileiros são influenciadas pelas suas disputas socioambientais e são parte das mobilizações desses povos pelo reconhecimento integral de direitos.

Palavras-chave Conflitos ambientais, Povos indígenas, Saúde indigena 


\section{Introdução}

Segundo o Censo 2010' , atualmente cerca de 817 mil pessoas se autodeclaram indígenas no Brasil, ou $0,43 \%$ da população. Enquanto a população brasileira cresceu cerca de $30 \%$ nos últimos 20 anos, a parcela indígena cresceu $177 \%$. Esses dados apontam para uma tendência de reversão do decrescimento demográfico que no passado ameaçava os povos indígenas no Brasil ${ }^{2}$.

Além do crescimento vegetativo da população, este fenômeno está associado ao recente fortalecimento de articulações sociopolíticas indígenas que catalisaram processos de reemergência étnica verificados em várias partes do País, principalmente nas regiões Sudeste e Nordeste. Muitas comunidades voltaram a reivindicar publicamente uma identidade associada às suas raízes ameríndias e a assumir uma posição de enfrentamento em relação aos processos que no passado as levaram a adotar estratégias de sobrevivência pelo ocultamento e indistinção em relação ao restante da população rural ${ }^{3}$.

Um fenômeno de grande importância, pois durante parte da história do Brasil os povos que sobreviveram à massacres, epidemias, escravidão, esforços de catequização e ou de integração forçada à sociedade nacional, bem como aos impactos da expansão econômica sobre seus territórios, estiveram submetidos a uma cidadania tutelada baseada na tese de uma suposta incapacidade relativa. Dessa forma, com o crescimento do espírito de luta entre esses povos, cresce também a luta por autonomia política e o reconhecimento de seus direitos culturais, territoriais e às demandas por políticas públicas que dialoguem com suas especificidades étnicas ${ }^{4,5}$.

Uma das principais conquistas do movimento indígena contemporâneo, após a promulgação da Constituição de 1988 (CF88), foi o fim do regime tutelar e o reconhecimento da plena cidadania deles, baseada no respeito à sua organização social, costumes, tradições, crenças, língua, manifestações culturais, tendo no direito originário a seus territórios tradicionais, e no usufruto dos bens comuns, um de seus pilares ${ }^{6}$.

No campo da saúde pública estas manifestações se fortalecem no final do século XX. Em consonância com a ressignificação do direito à saúde, promovida pela Reforma Sanitária Brasileira, eles pressionaram por uma política específica para a saúde indígena. $\mathrm{O}$ marco desta luta foi a realização da $1^{\text {a }}$ Conferência Nacional de Proteção à Saúde do Índio, em 1986. Até então, a atuação do Estado nesse campo havia sido marcada por iniciativas pontuais e por campanhas de combate a doenças nas aldeias, que incluíam os povos indígenas como parte da população-alvo, mas sem qualquer contextualização de suas condições de vida ou especificidades socioterritoriais? ${ }^{7}$.

Apesar do Sistema Único de Saúde (SUS) ter sido criado em 1988, e sua Lei Orgânica datar de 1990, o Subsistema de Atenção à Saúde Indígena (SASI) só foi criado em 1999. A primeira medida nesse sentido foi a criação dos Núcleos Interinstitucionais de Saúde Indígena (NISI) da Fundação Nacional de Saúde (Funasa), propostos desde o I Fórum Nacional de Saúde Indígena (FNSI), realizado em abril de 1993. No mesmo ano ocorreu, por pressão do movimento indígena, a II Conferência Nacional de Saúde para os Povos Indígenas, que delineou as bases para a criação de um subsistema específico para atenção à saúde indígena, organizado a partir dos Distritos Sanitários Especiais Indígenas (DSEIs) e cujo controle social se daria através dos Conselhos Locais e Distritais de Saúde Indígena ${ }^{8}$.

O SASI foi criado através da Lei 9.836/1999, do deputado federal Sérgio Arouca, que incluiu um quinto capítulo na lei 8.080/1990\%. Porém, se a luta indígena pela saúde se fortaleceu nesse contexto, a literatura especializada mostra que há fragilidades tanto na efetivação dos seus direitos sociais e territoriais quanto do direito à saúde.

Por exemplo, apesar de a Política Nacional de Atenção à Saúde Indígena (PNASI) garantir aos povos indígenas direito ao "acesso à atenção integral à saúde, de acordo com os princípios e diretrizes do SUS, contemplando a diversidade social, cultural, geográfica, histórica e política (...) reconhecendo a eficácia de sua medicina e o direito desses povos à sua cultura"10, estudos apontam que os serviços de saúde estruturados no âmbito do SASI em grande parte ainda se baseiam numa perspectiva médico-curativa, que propõem oferecer aos povos indígenas os benefícios da biomedicina, sem, contudo, estabelecer formas de diálogos interculturais?.

Assim, enquanto os profissionais de saúde nativos, principalmente os agentes indígenas de saúde (AIS), são formados dentro da racionalidade biomédica, os profissionais não-indígenas das Equipes Multidisciplinares de Saúde Indígena (EMSIs) não são devidamente preparados para compreender as diferenças étnicas e dialogar com as concepções nativas de saúde, doença, corpo e cuidado $^{11}$.

A complementaridade entre os DSEIs e as demais redes de atenção do SUS também é problemática. Os Polos-base nas aldeias são estru- 
turados para oferecer apenas atenção primária, referenciando os casos de média e alta complexidade para unidades do SUS localizadas nos perímetros urbanos ou em outros municípios. Nesta 'transição', diferenças organizacionais, culturais, linguísticas e fatores sociopolíticos acarretam dificuldades adicionais para os usuários indígenas, refletindo negativamente tanto na possibilidade de acesso quanto na qualidade do cuidado oferecido $^{12}$.

Todos esses processos contribuem para a manutenção de situações de saúde desfavoráveis para a população indígena. De acordo com o I Inquérito Nacional de Saúde e Nutrição dos Povos Indígenas $^{13}$, há uma forte relação entre contextos socioambientais injustos, processos históricos de expropriação, discriminação, ameaças à integridade dos territórios tradicionais, condições adversas de vida e desestruturação dos sistemas nativos de subsistência e autocuidado, que levam a cenários nos quais diversos desses povos vivem processos de vulnerabilização e desvantagem em relação a outros segmentos da população nacional, mesmo quando comparados com as frações mais pobres da sociedade brasileira.

Dessa forma, transformações sociais, culturais, ambientais e econômicas contribuíram para que problemas de saúde característicos da pobreza e da vulnerabilidade social, como as doenças infectoparasitárias (principalmente tuberculose, malária e parasitas intestinais), anemia e desnutrição, permaneçam importantes no quadro de morbimortalidade, ainda que em muitos desses povos já tenham iniciado um processo de transição epidemiológica, no qual as doenças crônicas teriam maior relevância nas taxas de mortalidade ${ }^{13}$.

Tais processos são intensificados por políticas de crescimento econômico baseadas no avanço das fronteiras da produção de commodities agrícolas e minerais, bem como por programas federais para expansão da infraestrutura de transportes e geração de energia que desconsideram os impactos sobre os territórios ocupados pelos povos indígenas. Esta tendência, ao mesmo tempo em que permite a incorporação de novas áreas à economia de mercado global, desestabiliza as organizações sociais preexistentes, afetando o exercício de sua territorialidade e modos de vida, ao ameaçar tanto as relações culturais e simbólicas estabelecidas com os territórios quanto as formas tradicionais de apropriação dos bens comuns.

Ambas são, muitas vezes, baseadas em regras de uso comum que outrora garantiam reprodução da biodiversidade, da água e de outros elementos necessários à sustentabilidade dos ecos- sistemas e à manutenção da vida. Contudo, hoje, elas estão sendo inviabilizadas pelos efeitos negativos dos grandes projetos apresentados pelos grupos corporativos e pelo Estado como indutores do desenvolvimento econômico e social.

Tal incompatibilidade entre a lógica de intervenção dos projetos econômicos e o modo de vida dos povos indígenas mobiliza-os a construir ações coletivas para defesa dos territórios, dos bens comuns e da vida. Estas estratégias estão na gênese dos conflitos ambientais, definidos como $^{14}$ :

Aqueles em que certos sujeitos coletivos alegam que a continuidade das práticas espaciais necessárias à sua reprodução mostra-se comprometida pelas escolhas técnicas e locacionais de empreendimentos cujos efeitos sobre recursos ambientais não mercantis como o ar, as águas e os sistemas vivos são tidos por indesejáveis.

Eles são desencadeados ou potencializados por situações de injustiça ambiental, isto é, por mecanismos sociais, políticos e econômicos que distribuem os riscos ambientais segundo uma lógica que se beneficia das desigualdades socioambientais e assimetrias de poder para destinar as atividades perigosas ou ambientalmente degradantes aos territórios de grupos socialmente vulnerabilizados e discriminados ${ }^{15}$.

Neste artigo, iremos explorar algumas inter -relações entre os processos de organização política e mobilização social de alguns povos indígenas brasileiros para enfrentamento dos processos sociais que levam à vulnerabilização socioambiental associada ao histórico de exclusão sociopolítica e à luta pelo direito à saúde.

\section{Métodos}

Baseamo-nos aqui na pesquisa intitulada "Mapa de conflitos envolvendo injustiça ambiental e saúde no Brasil"16, desenvolvida desde 2008 por um grupo de pesquisadores da Fundação Oswaldo Cruz (Fiocruz) articulados com diversos movimentos sociais ligados à Rede Brasileira de Justiça Ambiental (RBJA), e com o apoio do Ministério da Saúde.

Esta pesquisa foi realizada a partir de uma ampla revisão de literatura e análise documental visando o resgate do histórico de mobilizações associadas a alguns dos conflitos ambientais atualmente em curso no País. Para tanto foram utilizados como fontes de pesquisa documentos e publicações da RBJA, dos Ministérios Públicos e de diversas entidades ou grupos de pesquisa 
acadêmicos que atuam como parceiros técnicocientíficos de povos e comunidades envolvidas em situações de conflitos. Buscamos identificar as consequências das transformações socioambientais sobre o modo de vida e a saúde das comunidades, bem como as estratégias de resistência para superação dos problemas enfrentados.

Foram coletadas tanto informações mais estruturadas sobre os contextos, antecedentes e consequências dos conflitos, produzidas no âmbito de estudos realizados nas universidades ou em unidades técnico-científicas de diversas instituições públicas, quanto discursos e narrativas dos atores sociais envolvidos ou de suas organizações representativas a respeito de cada situação. Isso permitiu identificar como o debate público a respeito dos riscos ambientais e das suas consequências sociais e/ou sobre a saúde, bem como das propostas de alternativas ao modelo de desenvolvimento hegemônico, foram socialmente construídos e quais estratégias os agentes utilizaram para defender suas demandas nos diversos campos sociais nos quais foram obrigados a interagir.

Todas as informações veiculadas no Mapa de Conflitos estão disponíveis em uma página na internet e foram registradas a partir de um formulário digital construído com tecnologia do Departamento de Informática do SUS (Datasus).

Até o presente momento este projeto já mapeou quase 600 conflitos ambientais por todo o Brasil. Cada conflito é classificado segundo sua localização geográfica, o processo produtivo associado, o tipo de população afetada (a partir de uma perspectiva de autoidentificação que leva em consideração a sociodiversidade que pode existir em uma mesma comunidade, município ou região e a possibilidade de um mesmo conflito abranger territórios de um conjunto de comunidades socialmente diversas), os impactos ou riscos ambientais identificados ou denunciados, as consequências sobre a saúde das populações e as articulações que as comunidades constroem para enfrentamento dessas situações.

Neste artigo iremos explorar apenas os resultados de uma amostra dos casos existentes no banco de dados. Para seu estabelecimento, o primeiro critério de seleção foi o tipo de população atingida. Neste caso, selecionamos apenas os conflitos que direta ou indiretamente envolviam povos indígenas, num total de 160 casos, utilizamos esta amostra para realizar um breve panorama de tais conflitos, apresentado na primeira parte dos resultados deste artigo.

Em seguida realizamos uma segunda amostragem a fim de identificar as estratégias de mobilização dos povos indígenas. Como nosso principal interesse era analisar como tais situações resultaram em demandas para o SASI, como eram apresentadas e que tipo de estratégias eram utilizadas, o campo de busca por palavras-chaves do Mapa de Conflitos nos auxiliou na seleção dos casos que contivessem termos como "Funasa", "Sesai", "DSEI", "Casai", "Polo-base" e as versões extensas das siglas. Foram excluídos nessa filtragem aqueles resultados em que o SASI era citado apenas como fonte de informações e os casos repetidos.

Para análise dos dados foi construída uma matriz na qual organizamos as informações existentes no Mapa de Conflitos segundo a localização geográfica, os povos envolvidos, as atividades geradoras de injustiça ambiental, as organizações de representação indígena, os riscos à saúde, as demandas encaminhadas ao SASI ou a outras instituições estatais, as estratégias de luta e as respostas do SASI e das demais instituições.

\section{Resultados e discussão}

Estima-se que atualmente vivam no Brasil pelo menos 246 povos indígenas, falantes de cerca de 150 línguas $^{17}$. Segundo dados do IBGE $^{1}$, cerca de $78 \%$ dessa população está localizada nos estados das regiões Norte (37\%), Nordeste (25\%) e Centro-Oeste $(16 \%)$, que também contém a maior parte das terras indígenas que hoje estão em alguma fase do processo administrativo de demarcação $(57 \%, 12 \% \text { e } 21 \% \text { respectivamente })^{18}$. Da mesma forma, em nosso estudo, identificamos que essas regiões também concentram a maior parte dos conflitos socioambientais envolvendo povos indígenas no Brasil. Dos 160 casos que analisamos, a maior concentração de casos se encontra na região Norte (43\%); a seguir estão as regiões Centro-Oeste (25\%) e Nordeste (15\%).

Ao analisarmos esta informação concomitantemente ao levantamento dos principais processos produtivos associados a estes conflitos fica claro que esta tendência está associada um modelo de desenvolvimento regional baseado no avanço do agronegócio por meio das monoculturas $(32 \%)$, madeireiras $(23 \%)$, pecuária (18\%), pesca industrial e aquicultura (8\%).

Tais conflitos ainda são agravados pelas disputas em torno do uso, abuso ou controle de tecnologias perigosas, poluentes ou ainda outras cujos riscos para a saúde humana e o meio ambiente incluem um alto grau de incerteza, como os agrotóxicos e os transgênicos ${ }^{19}$. 
A mineração (18\%) também gera importantes impactos sobre os territórios e as comunidades indígenas. Apesar do reconhecimento do direito indígena à terra, o subsolo nacional é patrimônio da União, cuja exploração em terras indígenas somente poderia ser realizada após o expresso consentimento dos povos que as habitam, mas nem sempre tal direito é respeitado.

Outro foco de tensão nesses territórios são as obras de infraestrutura para atendimento às necessidades energéticas e logísticas do setor produtivo: usinas hidreoelétricas (28\%) e hidrovias, rodovias, minerodutos ou similares (14\%) também geram conflitos ambientais.

Estes se intensificaram no Brasil a partir de 1950, pois a modernização conservadora do campo permitiu o aumento da produtividade do agronegócio, a partir de uma estrutura fundiária historicamente marcada pela violência e pelas desigualdades. Outros fatores que os potencializam são de ordem ideológica, como as disputas entre os distintos significados da terra (como mercadoria $\mathrm{x}$ para o trabalho e reprodução do modo de vida) ou as disputas políticas em torno da legislação que garante os territórios tradicionais e impede a transformação dos bens comuns da natureza e interesse social em mercadorias ${ }^{20}$ realizada principalmente através da bancada ruralista no Congresso Nacional, que tem proposto diversas medidas para flexibilizar a legislação existente de forma a garantir a "mercadorização" da terra.

No caso específico das terras indígenas, a CF88 estabelece que os povos indígenas têm direito ao seu usufruto exclusivo, e a Convenção 169 da Organização Internacional do Trabalho (OIT), que elas não podem ser desapropriadas ou exploradas sem o seu consentimento livre, prévio e informado. Muitos povos utilizam a Convenção como estratégia de luta contra empreendimentos que colocam em risco seu território, com destaque para o Protocolo de Consulta elaborado pelos Munduruku, criado para orientar o Estado quanto à forma de consulta, suas expectativas, quem deve ser envolvido e o processo decisório. Isto modifica o campo de lutas, pois eles passam a estabelecer os termos do processo ${ }^{21}$.

Isto é importante se considerarmos que tramitam no Congresso Nacional diversas Propostas de emendas à Constituição (PECs) com o objetivo de repassar para o legislativo a demarcação de terras indígenas e a ratificação das já homologadas. Englobadas na PEC 215/2000²2, elas podem, se aprovadas, permitir a redução ou extinção de TIs para apropriação das terras pela mineração ou pelo agronegócio.
Teoricamente, uma vez que uma área é identificada pelo órgão indigenista como terra indígena, assegurar sua integridade e proteção deveriam ser prioridade nas disputas judiciais em curso, já que são consideradas pela CF88 como indisponíveis e inalienáveis ${ }^{23}$. Mas, inúmeros casos apontam que frequentemente o judiciário privilegia a reivindicação de direitos individuais por produtores rurais face aos direitos coletivos indígenas, o que resulta em desapropriações, violência policial e na desestruturação das formas tradicionais de ocupação do território.

Mesmo quando uma parcela do território permanece ocupada pelos povos indígenas, isto pode se tornar insuficiente, pois áreas importantes para sua reprodução cultural e para subsistência são privatizadas ou degradadas. Em ambos os casos, práticas tradicionais de manejo dos ecossistemas são inviabilizadas e a concentração populacional nas áreas remanescentes impacta diretamente no modo de vida das comunidades. Por exemplo, formas tradicionais de resolução dos conflitos, como a cisão das aldeias, são impedidas, o que aumenta as tensões internas dos grupos. As contaminações do solo, do ar e das águas contribuem para a descontinuidade do regime tradicional de uso dos bens comuns.

Além disso, a intensificação das disputas se traduz em violência. Em pelo menos 50\% dos casos analisados, um ou mais membros das comunidades envolvidas tiveram suas vidas ameaçadas. Entre 15 a 20\% dos casos, estas ameaças se concretizam em coação física, lesões corporais ou assassinatos. A violência tem sido prioritariamente direcionada contra as lideranças, o que sugere que ela é usada pelos grupos econômicos como uma estratégia de desmobilização da organização política dos povos envolvidos.

Esses resultados são consistentes com outros já divulgados sobre conflitos envolvendo povos indígenas. Por exemplo, na edição de 2013 do seu relatório "Violência contra os povos indígenas no Brasil", o Conselho Indigenista Missionário (Cimi) contabilizou pelo menos 53 assassinatos, 29 tentativas de assassinato, 13 homicídios culposos e 14 ameaças de morte contra indígenas naquele ano $^{24}$.

Outro risco importante à saúde indígena nesses contextos é a escassez de alimentos relacionada à diminuição ou degradação das áreas de plantio, da disponibilidade de pescado em rios cada vez mais poluídos por agrotóxicos e outros dejetos lançados nas bacias hidrográficas pelas áreas urbanas próximas ou ainda pela redução das áreas florestais pelo desmatamento. Isso ex- 
plica um elevado número de casos onde foram relatadas situações de insegurança alimentar que são geradas ou intensificadas pela desapropriação territorial ou pela degradação ambiental.

Além disso, pobreza e desigualdades ambientais aumentam a dependência desses povos da ajuda do Estado, pressionando-os a recorrer a políticas públicas que desconsideram suas tradições alimentares. Um estudo identificou que a dieta dos Terena do Mato Grosso do Sul tem sido determinada pelos itens constantes nas cestas básicas que recebem do Governo do Estado uma vez que a caça e coleta nas matas ficaram cada vez mais raras pela redução territorial ${ }^{25}$.

\section{Demandas e estratégias de mobilização indígena pela saúde}

Apesar da extensão dos conflitos ambientais nos quais os povos indígenas brasileiros estão envolvidos, dos cerca de 160 casos de conflitos ambientais analisados, somente 15 casos atenderam aos critérios de seleção para análise do histórico de luta pela saúde, a qual apresentamos a partir de agora.

São casos que envolvem comunidades situadas em 12 estados, com povos e contextos econômicos e socioambientais bastante diversos, como os Galibi, Karipuna e Palikur, no Amapá; diversas etnias do Vale do Javari/AM; os Tupinambá e os Pataxó na Bahia; os Xakriabá em Minas Gerais; os Tingui-Botó em Alagoas; os Terena no Mato Grosso do Sul; os Bororo no Mato Grosso; e os Kaingang no Paraná.

Suas principais demandas são por melhorias na infraestrutura dos DSEIs, que na maioria dos casos não contam com uma estrutura eficiente para dar resposta aos problemas de saúde gerados ou potencializados pelo contexto socioambiental onde vivem. Em suas cartas e documentos, são recorrentes as reclamações quanto à precariedade dos prédios, falta de medicamentos, equipamentos, meios de transporte e de comunicação para execução das atividades. Tais narrativas exprimem a forma como esses grupos representam suas vivências como usuários do SASI e reformulam-nas como proposições coletivas, seja cobrando a execução do que já está previsto na PNASI, seja exigindo a reformulação das práticas que consideram inadequadas.

Nos D da Amazônia, por exemplo, são recorrentes as denúncias quanto à indisponibilidade de barcos ou aviões necessários para percorrer rapidamente as grandes distâncias entre as aldeias e as unidades de saúde. Em muitos casos, a falta de infraestrutura leva à morte. Como o caso de um idoso Mayoruna que, em fevereiro de 2013, veio a falecer na aldeia Fruta Pão porque o barco que servia ao DSEI de Atalaia do Norte/ AM estava sem combustível ${ }^{16}$.

Por outro lado, apesar dos territórios indígenas serem frequentemente impactados pela construção de empreendimentos para geração de energia, muitos polos-base sofrem com a falta de eletricidade. Mesmo quando há geradores, a instabilidade no fornecimento de combustível, ou a falta de manutenção adequada, pode levar ao frequente desligamento dos refrigeradores, afetando a continuidade de programas de vacinação ou levando ao desperdício de medicamentos ${ }^{16}$.

Tais situações impõem a discussão a respeito da urgência de se repensar as formas como os polos-base são estruturados e a necessidade de implantar alternativas mais confiáveis e sustentáveis de fornecimento de energia para esses locais, como a implantação de células fotoelétricas, por exemplo.

A precariedade das Casas de Saúde Indígena (Casai) também tem sido objeto de recorrente reclamação e demanda por parte dos povos indígenas. Previstas pela PNASI ${ }^{10}$ como espaços de permanência de pacientes em tratamento fora de suas aldeias, deveriam possuir:

Condições de receber, alojar e alimentar paciente encaminhado e acompanhante, prestar assistência de enfermagem 24 horas por dia, marcar consultas, exames complementares ou internação hospitalar, providenciar o acompanhamento dos pacientes nessas ocasiões e o seu retorno às comunidades de origem, acompanhados das informações sobre o caso.

Gomes ${ }^{26}$ salienta que "embora denominadas Casas de Saúde Indígena, essas estruturas não executam ações médico-assistenciais", pois, apesar de algumas vezes contarem com a presença de enfermeiros, técnico de enfermagem, auxiliares de enfermagem, assistentes sociais, psicólogos, médicos, farmacêuticos, etc... Estes estão presentes apenas para garantir os encaminhamentos necessários e o bem-estar dos usuários indígenas durante sua estada. A atenção e o cuidado especializados, ou de maior complexidade, devem ser realizados pelas unidades de saúde do SUS para onde foram referenciados. As CASAIs foram previstas como um ponto de apoio fora das aldeias que auxiliariam o usuário indígena na transição do DSEI para outras instâncias do SUS.

A realidade, no entanto, é bastante distinta.

Em Lábrea/AM, por exemplo, os índios Paumari denunciavam, em agosto de 2011, que na 
Casai do município não havia alimentos nem água há pelo menos dois meses, motivo pelo qual foram buscar apoio na unidade em Porto Velho/ RO. Entretanto, sua permanência ali foi negada por serem oriundos de área fora da abrangência daquela unidade. Foi necessária a intervenção do Ministério Público Federal (MPF) para que recebessem o apoio que buscavam ${ }^{16}$.

Além disso, a contratação de profissionais de saúde para composição das EMSIs é outra demanda recorrente. Em pelo menos 11 casos, faltavam médicos e as equipes contavam apenas com enfermeiros/as, técnicos/as de enfermagem ou AISs para o atendimento. Mesmo quando os médicos existiam, eles visitavam as unidades esporadicamente, o que prejudicava o acompanhamento à saúde da população.

Uma situação que a partir de 2015 começou a ser enfrentada pelo MS, que ampliou a oferta de médicos nos DSEIS de 247, em 2011, para 582 naquele ano. Destes, pelo menos 300 eram estrangeiros ou brasileiros formados no exterior contratados no âmbito do Programa Mais Médicos ${ }^{27}$.

Tanto as reivindicações indígenas quanto o programa federal podem ser entendidos como respostas a um problema fundacional do SASI. Desde os primeiros anos de atuação da Funasa como órgão responsável pelo SASI, a principal forma de operacionalização dos DSEIs é através da política de terceirização e do estabelecimento de convênios com repasses de recursos para organizações não-governamentais, prefeituras e associações indígenas para que estas executassem as ações de saúde.

A incorporação das organizações sociais já presentes nos territórios propiciou o estabelecimento de "uma rede mínima" de unidades de saúde e, em alguns casos, permitiu aos povos indígenas algum nível de autonomia na execução das ações de saúde ${ }^{9}$, servindo como uma forma de "captação" de bens, recursos e serviços necessários à redução das iniquidades em saúde ${ }^{28}$. Por outro lado, esse processo também exigiu que essas organizações incorporassem em suas práticas as capacidades técnico-burocráticas necessárias à gestão e à prestação de conta dos recursos repassados; frequentemente elas não estavam preparadas para tais exigências, o que resultava em descontinuidades no repasse de recursos, dificuldades de manutenção do pessoal e precarização da assistência9.

A partir de 2006, diante da intensificação "dos problemas recorrentes de má gestão, autoritarismo, uso político e corrupção nas coordenações regionais e instâncias centrais da Funasa", muitas organizações indígenas passaram a propor modificações na organização do subsistema e maior institucionalidade dentro do MS. Após sucessivas mobilizações do movimento indígena, o Governo Federal criou a Secretaria Especial de Saúde Indígena (Sesai) ${ }^{8}$.

Após a criação da Sesai, o processo de terceirização que caracterizou a gestão da Funasa continuou, mas se tornou mais exigente e concentrado. Hoje, apenas três entidades privadas sem fins lucrativos estão conveniadas: a Missão Evangélica Caiuá (15 DSEIs), a Associação Paulista para o Desenvolvimento da Medicina (SPDM, 15 DSEIs) e o Instituto de Medicina Integral Prof. Fernando Figueira (IMIP, 5 DSEIs) ${ }^{9}$.

Num cenário como esse, para possibilitar maior diálogo com o SASI e numa tentativa de melhorar o atendimento, muitos povos indígenas têm reivindicado maior participação no processo de nomeação dos gestores, sendo a substituição destes, quando considerados incapazes ou inadequados para o cargo, uma demanda recorrente de suas associações ${ }^{16}$.

A participação e o controle social do SASI são previstos na PNASI, contudo, alguns estudos apontam que eles estão longe de serem efetivos. A lógica que orienta as formas de controle social no SASI, por vezes, é contraditória com as organizações sociais e políticas dos povos indígenas e incompatível com o tipo de participação decisória mais direta que muitas delas demandam ${ }^{28}$.

Por fim, encontramos uma demanda recorrente cuja resolução, apesar de poder ser compreendida como um problema para o qual o sistema de saúde pode contribuir, não é atribuição direta do SASI. Estamos nos referindo ao enfrentamento da violência característica dos contextos de conflito ambiental que pressiona SASI/SUS na medida em que as vítimas ou seus parentes devem ser tratados e acompanhados em relação às sequelas que muitas vezes vão além dos danos físicos. Além disso, são demandas que pressionam por uma atuação integrada entre os poderes e os diversos setores do Estado, principalmente o judiciário e as comissões de direitos humanos, e cujas raízes estão mais profundamente ligadas ao contexto social e territorial.

Para pressionar pelo atendimento dessas demandas, muitas organizações políticas indígenas têm se utilizado de diversas estratégias de luta, que podem ser agrupadas da seguinte forma:

a) denúncias e divulgação de conhecimento construído com as comunidades locais:

Neste grupo estão incluídas as numerosas cartas publicadas pelas entidades representati- 
vas das comunidades em seus veículos próprios de comunicação, de entidades parceiras, redes de movimentos sociais ou através de entrevistas concedidas à imprensa.

Através de seus parceiros nos MPs, entidades de defesa dos direitos humanos ou-parlamentares engajados com a causa indígena, elas frequentemente conseguem que tais documentos se constituam como parte de processos administrativos, judiciais, figurem como pauta de audiências públicas, ou contribuam para a organização de seminários e debates.

Também inclui a divulgação de estudos independentes sobre a situação de saúde dos seus povos. Por exemplo, a partir de fevereiro de 2010, os índios do Vale do Javari passaram a se utilizar de um diagnóstico da saúde indígena, produzido pelo Centro de Trabalho Indigenista (CTI) em articulação com o saber acumulado pelas organizações indígenas e suas comunidades, para consubstanciar suas reivindicações junto à Sesai ${ }^{16}$.

Tal estratégia é importante, se levarmos em consideração que há espaços onde o saber dos povos indígenas pode ser deslegitimado face ao conhecimento produzido cientificamente e tem sido utilizada com sucesso por comunidades envolvidas em conflitos ambientais em diversas partes do mundo ${ }^{29}$.

b) pressão por vias institucionalizadas:

Incluímos neste grupo tanto as estratégias de ocupação e disputa dos espaços de controle social dentro do SASI quanto o encaminhamento de solicitações, documentos ou abaixo-assinados direcionados ao subsistema ou denúncias às autoridades policiais, MPs e às comissões de direitos humanos nacionais e internacionais.

Ao analisarmos o tipo de reivindicações que os povos indígenas encaminham aos MPs e às $\mathrm{CDHs}$, percebemos que estas instituições costumam ser acionadas quando as negociações diretas com o SASI são insuficientes, ou quando a continuidade da violação de determinado direito coloca em risco sua integridade física, a sustentabilidade dos territórios ou suas organizações sociais. Há também casos de mobilização dirigida ao legislativo, como, em 2008, quando a Comissão de Segurança Pública da Assembleia Legislativa de Minas Gerais coordenou uma audiência pública para discutir assassinatos relacionados às disputas pelo território Xakriabá ${ }^{16}$.

c) pressão por vias não institucionalizadas:

Há momentos, contudo, em que as estratégias de luta das comunidades exigem romper com as vias institucionais para pressionar o Estado. São incluídas nessa classificação as estratégias de ocupação de prédios públicos, a detenção de funcionários dos DSEIs; a apreensão de veículos ou as manifestações públicas. Apesar de romperem com os trâmites normais do Estado, o uso da não-violência nesses momentos garante a efetividade da pressão pela abertura de canais de negociação e evita que a força policial seja utilizada.

Entre os casos analisados, a estratégia de ocupação de prédios públicos foi acionada em pelo menos sete ocasiões. Em um caso, um grupo de 150 Xakriabás ocupou o polo-base em São João das Missões/MG, em agosto de 2013, em protesto contra a gestora local ${ }^{16}$. Tais ações frequentemente mobilizam mais de uma etnia, ativando articulações políticas em momentos críticos.

Ocupar fisicamente espaços para pressionar o Estado também tem sido uma estratégia comumente utilizada pelo movimento indígena nas lutas socioambientais. A ocupação de terras ou escritórios da Funai, por exemplo, é um expediente comum nessas situações, numa estratégia para pressionar por avanços no trâmite burocrático e efetivar direitos já reconhecidos pela legislação.

\section{Conclusão}

Os casos analisados neste artigo apontam para conquistas do movimento indígena brasileiro no campo das lutas por reconhecimento de direitos e pressões pela efetivação de políticas públicas de saúde que reconheçam sua diversidade cultural. Entretanto, a morosidade e ineficiência da gestão ou dos espaços institucionalizados de controle social do SASI têm levado os povos indígenas a recorrer às arenas legislativa e judicial para pressionar o Estado a assegurar seu direito à saúde. Na ausência de respostas nesses espaços, eles não hesitam em utilizar estratégias de ocupação de espaços públicos para pressionar por soluções.

Nos contextos de conflito, os direitos dos povos indígenas somente se realizam se garantidos de forma integral. Nesse sentido, podemos afirmar que o SASI/SUS precisa estar capacitado e atento para considerar os contextos socioambientais onde esses povos vivem, os quais frequentemente geram impactos significativos à sua saúde coletiva, insegurança alimentar, suicídios ou assassinatos e a assumir um papel mais relevante na luta contra a violência, pois esta é a face mais visível da influência dos conflitos sobre suas vidas.

Além disso, é importante que as instituições do setor enfrentem o desafio de exercer um papel mais relevante na defesa da saúde e dos direitos 
indígenas num momento de acirramento de conflitos e mudanças no quadro legislativo-institucional que tendem a vulnerabilizar ainda mais os povos indígenas no Brasil', devido à tendência de priorização da exploração predatória dos bens comuns ${ }^{30}$ em detrimento do bem viver ${ }^{31}$ que orienta o modo de vida de muitos povos indígenas.
Por isso, concluímos que as estratégias de luta pela saúde dos povos indígenas brasileiros são influenciadas pelas suas disputas socioambientais e dialogam com as mobilizações desses povos pelo reconhecimento integral de seus direitos, pressionando o sistema de saúde a atuar de forma mais articulada com os diversos órgãos estatais envolvidos com as políticas indigenistas.

\section{Colaboradores}

DF Rocha organizou os dados, trabalhou na concepção do texto e realizou a elaboração do texto inicial. MFS Porto e T Pacheco coordenaram a pesquisa, estabeleceram a metodologia e contribuíram para versão final do texto. 


\section{Referências}

1. Instituto Brasileira de Geografia e Estatística (IBGE). Os indígenas no Censo Demográfico 2010. Brasília: IBGE; 2012. [acessado 2014 Nov 28]. Disponível em: http://goo.gl/PyhXRf

2. Aparício AB. Direitos territoriais indígenas: diálogo entre o direito e a antropologia — o caso da Terra Guarani "Morro dos Cavalos" [dissertação]. Florianópolis: Universidade Federal de Santa Catarina; 2008.

3. Arruti JMA. Morte e vida no nordeste indígena: A emergência étnica como fenômeno histórico regional. Estud Hist 1995; 8(15):57-94.

4. Oliveira JP. Cidadania, racismo e pluralismo: a presença das sociedades indígenas na organização do EstadoNacional brasileiro. In: Ensaios de antropologia histórica. Rio de Janeiro: UFRJ; 1999. p. 192-208.

5. Peres S. Direitos indígenas no Brasil: A construção de uma cidadania etnicamente diferenciada. In: Souza, $\mathrm{SR}$, organizador. Que cidadania queremos? Rio de Janeiro: Livre Expressão; 2003. p. 109-145.

6. Araújo AV, Leitão S. Direitos indígenas: avanços e impasses pós-1988. In: Lima ACS, Barroso-Hoffmann M, organizadores. Além da Tutela. Rio de Janeiro: Contra Capa; 2002. p. 23-33.

7. Benevides L, Portillo JAC, Nascimento WF. A atenção à saúde dos povos indígenas do Brasil: das missões ao subsistema. Tempus 2014; 8(1):29-39.

8. Altini E, Rodrigues G, Padilha L, Moraes PD, Liebgott RA. A Política de Atenção à Saúde Indígena no Brasil. Brasília: CIMI; 2013. [acessado 2014 Nov 27]. Disponível em: http://goo.gl/jOWr3n

9. Cardoso MD. Saúde e povos indígenas no Brasil: notas sobre alguns temas e equívocos na política atual. Cad Saude Publica 2014; 30(4):860-866.

10. Fundação Nacional de Saúde (Funasa). Política Nacional de Atenção à Saúde dos Povos Indígenas. Brasília: Ministério da Saúde; 2002.

11. Diehl EE, Pellegrini MA. Saúde e povos indígenas no Brasil: o desafio da formação e educação permanente de trabalhadores para atuação em contextos interculturais. Cad Sapude Publica 2014; 30(4):867-874.

12. Azevedo ALM, Gurgel IGD, Tavares MA. O poder de acessar a saúde: uma análise do acesso à saúde na etnia indígena Xukuru do Ororubá, Pesqueira (PE). Cad Saúde Pública Coletiva 2014; 22(3):275-280.

13. Fundação Nacional de Saúde e Associação Brasileira de Pós-graduação em Saúde Coletiva. Inquérito nacional de saúde e nutrição dos povos indígenas: Relatório final (Análise de dados). Rio de Janeiro: Funasa, Abrasco; 2009. $\mathrm{N}^{\circ} 7$.

14. Acselrad H. A crítica do "ambiente" e o ambiente da crítica. Antropolítica 2014; 36:27-47.

15. Porto MFS. Complexidade, processos de vulnerabilização e justiça ambiental: Um ensaio de epistemologia política. Rev Crítica Ciên Soc 2011; 93:31-58.

16. Fundação Oswaldo Cruz (Fiocruz). Mapa de conflitos envolvendo injustiça ambiental e saúde no Brasil. 2015. [acessado 2015 Fev 12]. Disponível em: http://goo. $\mathrm{gl} / 7 \mathrm{yEfm} 5$

17. Instituto Socioambiental (ISA). Povos Indígenas no Brasil. Brasília: ISA; 2010. [acessado 2014 Nov 27]. Disponível em: http://goo.gl/8xEJWe
18. Fundação Nacional do Índio (Funai). Lista TI Brasil. Brasília: Funai; s.d. [acessado 2014 Nov 28]. Disponível em: http://goo.gl/22vqLf

19. Porto MFS, Soares WL. Modelo de desenvolvimento, agrotóxicos e saúde: um panorama da realidade agrícola brasileira e propostas para uma agenda de pesquisa inovadora. Rev Bras Saúde Ocup 2012; 37(125):17-31.

20. Delgado G. A Questão Agrária no Brasil, 1950-2003. In: Jaccoud L, organizador, Questão social e políticas sociais no Brasil contemporâneo. Brasília: IPEA; 2005. p. 51-90.

21. Movimento Munduruku Ipereg Ayu. Protocolo de consulta Munduruku. 2014. [acessado 2017 Jan 18]. Disponível em: https://goo.gl/jbam3n

22. Câmara dos Deputados. PEC 215/2000. [acessado 2015 Fev 13]. Disponível em: http://goo.gl/C21Fr0

23. Duprat D. Terras indígenas e o judiciário. Documentose publicações. Brasília: MPF; s.d. [acessado 2015 Fev 13]. Disponível em: http://goo.gl/iBaCYS.

24. Conselho Indigenista Missionário (CIMI). Relatório Violência contra os Povos Indígenas no Brasil - Dados de 2013. [acessado 2015 Fev 13]. Disponível em: http:// goo.gl/sctKgx

25. Ribas DLB, Philippi, ST. Aspectos alimentares e nutricionais de mães e crianças indígenas Terena, Mato Grosso do Sul. In: Coimbra Júnior CEA, Santos RV, Escobar AL, organizadores. Epidemiologia e saúde dos povos indígenas no Brasil. Rio de Janeiro: Fiocruz, Abrasco; 2005. p. 73-88.

26. Gomes JS. "Casas de Saúde" e assistência farmacêutica: Desafios da saúde indígena em Belém e Macapá. [dissertação]. Belém: Universidade Federal do Pará, Universidade Federal do Amazonas, Centro de Pesquisa Leônidas \& Maria Deane; 2008.

27. Brasil. Ministério da Saúde (MS). Programa leva mais atendimentos à saúde dos povos indígenas. 22 Jul 15. [acessado 2016 Out 04]. Disponível em: https://goo.gl/ OHsI9U

28. Garnelo L, Sampaio S. Bases socioculturais do controle social em saúde indígena. Problemas e questões na Região Norte do Brasil. de Publica 2003; 19(1):311-317.

29. Porto MFS, Rocha DF, Finamore, R. Saúde coletiva, território e conflitos ambientais: bases para um enfoque socioambiental crítico. Cien Saude Colet 2014; 9(10):4071-4080.

30. Leroy JP. Mercado ou bens comuns? Rio de Janeiro: Fase; 2016.

31. Acosta A. O bem viver. São Paulo: Aut. Literária Elefante; 2016.

Artigo apresentado em 13/06/2016

Aprovado em 16/03/2017

Versão final apresentada em 18/03/2017 